\title{
Uterine Artery Embolization in Women with Symptomatic Cervical Leiomyomata: Efficacy and Safety
}

\author{
Annefleur M. de Bruijn ${ }^{1}$ - Sven-Ole J. H. Adriaansens ${ }^{3} \cdot$ Marieke Smink $^{4}$ • \\ Alexander Venmans ${ }^{3}$ - Wouter J. K. Hehenkamp ${ }^{1}$ - Albert J. Smeets ${ }^{3}$. \\ Anthony Lopez ${ }^{2} \cdot$ Judith A. F. Huirne $^{1} \cdot$ Paul N. M. Lohle ${ }^{3}$
}

Received: 7 June 2018/Accepted: 17 September 2018/Published online: 4 October 2018

(C) The Author(s) 2018

\begin{abstract}
Purpose To perform an evaluation on safety and efficacy of uterine artery embolization (UAE) in the patients with symptomatic cervical leiomyomata.

Methods Patients with symptomatic cervical leiomyomata who underwent UAE in one specialized hospital were retrospectively analyzed, both clinically and with MR imaging. The 3-month outcomes were assessed with MR imaging and a validated questionnaire. Long-term followup was assessed by direct contact or file review. To determine the efficacy of UAE for cervical leiomyomata, the primary objective was to assess the clinical outcome with the UFS-QOL questionnaire, containing the healthrelated quality of life (HRQOL) and symptom severity score (SSS). To assess safety, the secondary objective included leiomyomata volume reduction, the infarction/complication rate and secondary interventions were needed.

Results Between 2006 and 2017, eight of 1180 patients underwent UAE and were eligible for inclusion. All
\end{abstract}

Electronic supplementary material The online version of this article (https://doi.org/10.1007/s00270-018-2081-2) contains supplementary material, which is available to authorized users.

Annefleur M. de Bruijn

a.debruijn@vumc.nl

1 Department of Gynecology, VU Medical Center, De Boelelaan 1117, 1007 MB Amsterdam, The Netherlands

2 Department of Radiology, The Royal Surrey County Hospital, Guildford, England, UK

3 Department of Radiology, Elisabeth Tweesteden ziekenhuis, Tilburg, The Netherlands

4 Department of Gynecology, Elisabeth Tweesteden Ziekenhuis, Tilburg, The Netherlands embolizations were technically successful $(n=8)$. At 3 months, all patients showed cervical leiomyomata volume reduction with a median reduction of $41.5 \%$ $\left(38.8 \mathrm{~cm}^{3}\right)$ compared to baseline $(p=0.012)$. No complications occurred. At a median follow-up of 3 months (range $1-7, n=7$ ), the HRQOL and SSS improved with a median difference of 13 points (range -5 to 60, $p=0.063$ ) and -13 points (range -79 to $3, p=0.046$ ), respectively. Long-term follow-up showed two secondary interventions (median of 43.5 months). Six patients reported no symptom recurrence.

Conclusion UAE in women with symptomatic cervical leiomyomata is effective and safe with significant improvement in symptoms and quality of life. UAE is a valuable option for women seeking a non-surgical solution.

Keywords Cervical leiomyomata - Uterine artery embolization · Health-related quality of life (HRQOL)

\section{Introduction}

Uterine leiomyomata are common benign tumors originating from neoplastic transformation of smooth muscle cells in the uterine wall [1]. Approximately $20-40 \%$ of women are affected in their reproductive age [2]. Uterine leiomyomata located in the cervix are rare, ranging from 0.9 to $8 \%$ of all uteri containing leiomyomata [3-5]. Symptoms associated with cervical leiomyomata are abnormal bleeding, pain (dysmenorrhea) and bulk-related symptoms [6]. Surgical treatment of cervical leiomyomata 
is difficult due to its location. Poor access to the operating field, suturing difficulty, poor cervical flexibility, increased blood loss and close neighboring organs (bladder, ureter and rectum) could hamper the procedure [7, 8]. UAE is an established valuable treatment alternative to surgery in the treatment of uterine fibroids located in the body or fundus of the uterus as reported in multiple randomized controlled trials [9-14]. Identification of the cervical vessels is complex and often differs in shape, size and location. Literature describes that the branches running toward the cervix are significantly variable in patients and shows that the vascular supply of the cervix seems to come from several vessels; however, these findings are based on postmortem studies [15-18]. Therefore, the localization of the afferent artery to the cervical perifibroid plexus is challenging. The aim of our study was to evaluate the efficacy and safety of UAE in the treatment of symptomatic cervical leiomyomata. This was achieved by using the validated standard UFS-QOL questionnaire including the health-related quality of life (HRQOL) and symptom severity score (SSS) $[19,20]$. In addition imaging outcomes, complications and secondary interventions were evaluated.

\section{Materials and Methods}

\section{Study Design}

This retrospective study evaluated all patients that underwent UAE for cervical leiomyomata from 2006 until 2017 in a single specialized hospital in the Netherlands. To determine the efficacy of UAE for cervical leiomyomata, the primary objective was to assess the clinical outcome using the validated standardized questionnaire Uterine Fibroid Symptom and Health-related Quality of Life (UFSQOL) at baseline and at 3 months after UAE, containing the health-related quality of life (HRQOL) and symptom severity score (SSS). To assess safety, the secondary objective included cervical leiomyomata volume reduction, the infarction/complication rate and secondary interventions needed. Inclusion criteria were (1) patients with leiomyomata-related complaints, i.e., abnormal uterine bleeding, pain (dysmenorrhea) and/or bulk-related symptoms, (2) MR imaging which confirmed the presence of a cervical leiomyomata with or without other uterine body leiomyomata, (3) leiomyomata treated with UAE and (4) the availability of 3 months post-embolization MR images. Exclusion criteria were (1) UAE during pregnancy and (2) UAE for postpartum hemorrhage. The local ethics committee approved this study. All patients gave their informed consent for retrospective review with a waiver for patients who were unable to be located.

\section{Study Measures} Magnetic Resonance Imaging (MRI) at Baseline
and Follow-Up (Short Term and Long Term)

All patients included underwent T1, T2 and T1 contrastenhanced (gadolinium) MR imaging at baseline and at 3 months following UAE. The diagnosis of a cervical leiomyomata was determined with MR imaging with the criterion of leiomyomata location at the cervix (intramu$\mathrm{ral} / \mathrm{submucous} /$ subserous) or attachment (pedunculated) to the cervix. Fibroid volume was calculated using the ellipsoid formula: length $\times$ width $\times$ height $\times 0.5233$. Two radiologists assessed after UAE the infarction rate by using the same volumetric measurement as mentioned above [21]. Insufficient infarction was determined at a cutoff point $<80 \%$ as described earlier by Smeets et al. [22].

\section{Angiographic Procedure}

UAE was performed according to local protocol and professional standards and reported as described by Goodwin et al. [23]. All patients received a drip infusion at the wrist and an intravenous patient-controlled analgesia pump for pain management. All UAE consisted of bilateral access in the common femoral arteries with placement of the $4 \mathrm{Fr}$ sheath and selective placement of a C2 catheter (Tempo Aqua C2, Cordis Corporation, Miami, USA) in both uterine arteries. Digital subtraction angiography (DSA) displayed the cervical leiomyomata vascularity. According to Kim et al. [24], the cervical leiomyomatas were classified based on vascular aspects during DSA: Grade I poor/minimal vascularity, without enhancement of the tumor; Grade II moderate vascularity, with limited enhancement in small vessels intratumorally; and Grade III pronounced staining of the leiomyomata, with large tortuous vessels. In addition to these intratumoral vascularity patterns, an overview is made of two types of afferent arteries identified during DSA (Fig. 1). Due to a lack of available information (sometimes lack of detailed DSA images of the previous procedures) and overprojection of Grade III tortuous vessels, not all the patients could be classified. However, the radiologists performing the embolization procedures described the different types of afferent arteries as seen during the procedures in their reports. Ideally, a catheterization technique was applied when possible with superselective placement of the (micro-)catheter tip into the uterine artery side branch, i.e., a separate cervical artery, in order to secure optimal embolization of the cervical leiomyomata. Initial treatment was focused on super-selective UAE of the cervical fibroid followed by standard UAE of the remaining uterine fibroids when present. Figure 1 displays an overview of the different afferent arteries 
Fig. 1 Overview of afferent branching arteries to cervical leiomyomata as identified during UAE. Note Boxes type 1, 2.1 and 2.2 are the locations of the catheters as used per subtype. Subtype 1 with a plexus of feeding branches to the cervical leiomyomata. Subtype 2.1 with a proximal single branch from uterine artery to the cervical leiomyomata. Subtype 2.2 with a distal single branch from uterine artery to the cervical leiomyomata. Type 2 cases were, when possible, superselectively catheterized
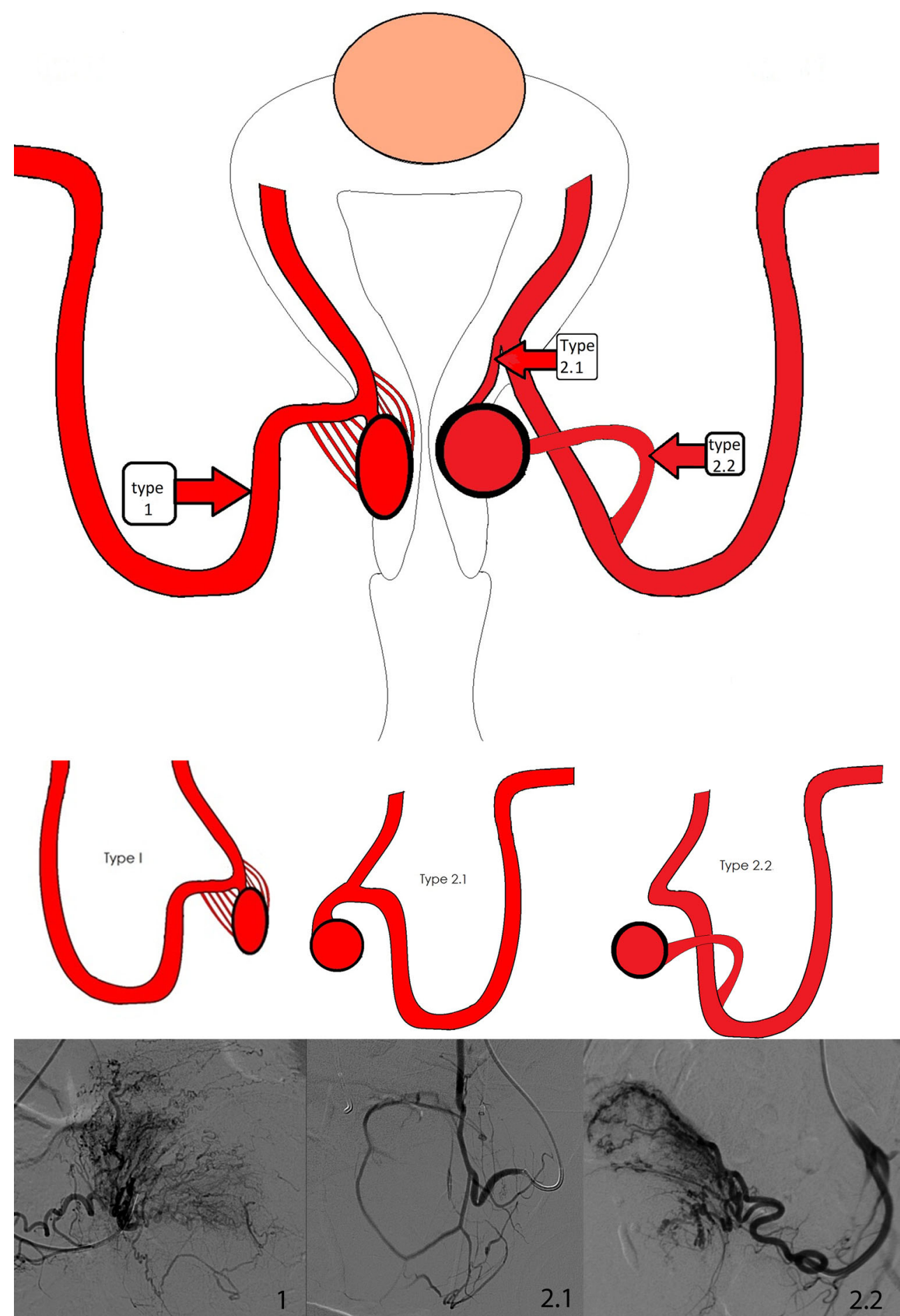

and the location of the catheter during UAE. Described in this cohort is the dominant side of the afferent artery. Type 1 is an often seen entity, wherein not only one afferent artery can be identified due to overprojection of an arterial plexus. Potentially, there is no solitary afferent artery, but only a plexus feeding the cervical leiomyomata. In Type 1 cases with an arterial plexus, the catheter tip was positioned at point A. Type 2 was identified in 3 cases, defined as a cervical leiomyomata with a single uterine artery branch, i.e., a solitary feeding cervical artery. In Type 2 cases, when possible, super-selective positioning of the catheter tip was applied into the afferent cervical artery. Type 2.1 is a solitary side branch originating proximal from the ascending segment of the uterine artery. Type 2.2 is a distal solitary side branch of the uterine artery. 
The embolization agents used were precisely calibrated microspheres, built of a hydrogel core and coated with a polymer Polyzene ${ }^{\circledR}-\mathrm{F}$ (Embozene ${ }^{\mathrm{TM}}$, Boston Scientific, Amsterdam, The Netherlands) ranging in size from 500 to $1200 \mu \mathrm{m}$ and additionally $700 \mu \mathrm{m}$ non-spherical polyvinyl alcohol (PVA) particles in one patient (Contour ${ }^{\mathrm{TM}}$, Boston Scientific, Amsterdam, The Netherlands). The angiographic embolization endpoint was at complete stasis. All patients received a periprocedural intravenous patientcontrolled analgesia pump, for adequate pain treatment. Complications were recorded.

\section{Clinical Assessment at Baseline and Follow-Up (Short Term and Long Term)}

Patients completed the standardized questionnaire, Uterine Fibroid Symptom and Health-related Quality of Life (UFSQOL) at baseline and at 3 months after $\operatorname{UAE}[20,25]$. Adverse events were recorded. Long-term clinical results were also obtained through a telephone-administered questionnaire and reviewing patients' files. The UFS-QOL rates the SSS on a scale of $0-100$ and the HRQOL on a scale of 0-100 in seven different domains: (1) concern, (2) activities, (3) energy/mood, (4) control, (5) self-consciousness, (6) sexual function and (7) HRQOL total score [20]. A lower SSS means improvement in symptoms. A higher HRQOL score indicates better quality of life. The duration of hospital stay was recorded.

\section{Statistical Analysis}

The Wilcoxon signed-rank test for paired samples was used to compare the cervical leiomyomata volumes, the UFSQOL including HRQOL and symptoms severity scores (SSS) during follow-up and at baseline. $P$ values $<0.05$ were considered statistically significant. SPSS (IBM SPSS Statistics, version 22) was used for statistical analysis.

\section{Results}

From a total of 1180 patients who underwent UAE during 2006 until 2017, 12 patients with proven cervical leiomyomata on MRI underwent UAE. Four of these patients were excluded due to pregnancy $(n=1)$, postpartum $(n=1)$, UAE of an acute bleeding leiomyomata expulsion as preparation for surgical removal $(n=1)$ and absence of a follow-up MRI $(n=1)$. The median age of all patients $(n=8)$ at baseline was 37.0 years, ranging from 33 to 47 years. Three patients showed concurrent non-cervical fibroid disease (Table 1, patients 6, 7 and 8). Table 1 lists baseline characteristics of these patients with symptomatic cervical leiomyomata (demographics, previous treatment, symptoms and concurrent leiomyomata) who underwent UAE (procedural characteristics). All eight UAEs were technically successful without complications. All patients were discharged from the hospital the next day, except one patient who needed one extra night due to persistent pain. After 3 months, one patient reported transient amenorrhea.

\section{Imaging Results}

All patients demonstrated volume reduction compared to baseline at 3 months after UAE (Table 2). Figure 2 displays a median leiomyomata volume reduction of $41.5 \%$ $\left(38.8 \mathrm{~cm}^{3}\right)$ at 3 months compared to baseline $(p=0.012)$. Five out of eight patients $(62.4 \%)$ displayed $\geq 80 \%$ infarction of the cervical leiomyomata. The grade pattern of these patients is displayed in Table 2. Three patients (no. 1, 7 and 8) demonstrated 50, 40 and $60 \%$ infarction of the cervical leiomyomata, respectively (Table 2). All of these patients had a Grade III leiomyomata.

Three out of eight patients (no. 6, 7 and 8) demonstrated concurrent non-cervical leiomyomata disease, and two of them (no. 7 and 8) received additional treatment. These two patients showed a cervical leiomyomata infarction rate of $40 \%$ and $60 \%$. In patient no. 8 , a concurrent anterior wall leiomyomata showed no infarction after the first UAE. Follow-up MRI demonstrated an unchanged uterine body leiomyomata and progressive enhancement of the cervical leiomyomata overtime. Results of the (technically successful) secondary UAE showed no additional infarction rate on the follow-up MRI. Patient no. 7 showed an infarction rate of $40 \%$ (cervical leiomyomata) after the initial UAE, with a volume reduction of nearly $63 \%$ $\left(216.7 \mathrm{~cm}^{3}\right)$. Due to persisting gynecological symptoms with complaints of mass effect, hysterectomy was eventually carried out. Figures 3 and 4 display the image changes in terms of aspect, volumes and contrast enhancement of cervical leiomyomata after UAE in patient no. 2 and 6.

\section{Clinical Results UFS-QOL: Short Term}

Seven of eight included women filled out the UFS-QOL at a median follow-up of 3 months (range 1-7). Figure 5 depicts the median HRQOL and SSS (both on a total scale of 100 points) at baseline and follow-up. The total HRQOL score showed a median, nonsignificant increase of 13 points (range -5 to $60 ; p=0.063$ ). The SSS demonstrated a statistically significant improvement compared to baseline and decreased with a median score of -13 points (range -79 to $3 ; p=0.046$ ). Appendix 1 in electronic supplementary material displays the median score of the separate domains. It shows an increase in HRQOL scores in every domain; however, only sub-domains concern 
Table 1 Patient demographics and procedural characteristics

\begin{tabular}{|c|c|c|c|c|c|c|}
\hline \multicolumn{4}{|c|}{ Patient demographics, previous treatment, symptoms } & \multicolumn{3}{|c|}{ Procedural characteristics } \\
\hline Patient & Age & Previous treatment & $\begin{array}{l}\text { Main } \\
\text { symptoms }\end{array}$ & Catheter & UAE material & $\begin{array}{l}\text { Hospital } \\
\text { stay }\end{array}$ \\
\hline 1 & 33 & Hormonal (oral) & $\mathrm{BRS}+\mathrm{WTC}$ & $\begin{array}{l}\text { 4Fr } \\
\text { sheath }+\mathrm{C} 2\end{array}$ & Microspheres 900-1100 $\mu \mathrm{m}$ & 1 \\
\hline 2 & 37 & NR & AUB + WTC & $\begin{array}{l}4 \mathrm{Fr} \\
\quad \text { sheath }+\mathrm{C} 2\end{array}$ & $\begin{array}{l}\text { Super-selective. Microspheres 500, } \\
\quad 700,900 \mu \mathrm{m} \text { (only left side) }\end{array}$ & 1 \\
\hline 3 & 33 & $\begin{array}{l}\text { Tranexamic acid, ulipristal. } \\
\text { Myomectomy } 2007 \text { and } 2015\end{array}$ & BRS + WTC & $\begin{array}{l}\text { 4Fr } \\
\text { sheath }+\mathrm{C} 2\end{array}$ & $\begin{array}{l}\text { Microspheres } 700,900,1300 \mu \mathrm{m} \text { and } \\
700 \mu \mathrm{m} \text { PVA }\end{array}$ & 1 \\
\hline 4 & 45 & NR & BRS & $\begin{array}{l}\text { 4Fr } \\
\text { sheath }+\mathrm{C} 2\end{array}$ & Microspheres 700-900 $\mu \mathrm{m}$ & 1 \\
\hline 5 & 38 & Hormonal (oral) & $\mathrm{P}$ & $\begin{array}{l}\text { 4Fr } \\
\text { sheath }+\mathrm{C} 2\end{array}$ & Microspheres 500, $900 \mu \mathrm{m}$ & 1 \\
\hline $6+$ & 47 & NR & AUB + BRS & $\begin{array}{l}\text { 4Fr sheath } \\
\quad+\mathrm{C} 2\end{array}$ & Microspheres 700, 900, 1200 & 1 \\
\hline $7+$ & 42 & No & AUB & $\begin{array}{l}\text { 4Fr } \\
\text { sheath }+\mathrm{C} 2\end{array}$ & $\begin{array}{l}\text { Microspheres 700-900 } \mu \mathrm{m} \text { and } \\
900-1200 \mu \mathrm{m}\end{array}$ & 3 \\
\hline $8+$ & 33 & Hormonal (oral) & $\mathrm{P}+\mathrm{AUB}$ & $\begin{array}{l}\text { 4Fr } \\
\text { sheath }+\mathrm{C} 2\end{array}$ & Microspheres 700-900 $\mu \mathrm{m}$ & 1 \\
\hline $\begin{array}{l}\text { Median } \\
\quad \text { (range) }\end{array}$ & $\begin{array}{l}37.5 \\
\quad(33-47)\end{array}$ & & & & & $1.0(1-3)$ \\
\hline
\end{tabular}

$N R$ not reported, $A U B$ abnormal uterine bleeding, $B R S$ bulk-related symptoms, $W T C$ wish to conceive, $P$ intermittent pain not related to the menstrual cycle

+ With concurrent non-cervical leiomyomata disease

$(p=0.043)$, control $(p=0.046)$ and self-consciousness

$(p=0.042)$ reached statistical significance.

\section{Clinical Outcomes: Long Term}

Long-term clinical follow-up with a median of 43.5 months (range 6-127, $n=8$ ) outlined the two secondary treatment cases. Patient no. 8 with concurrent noncervical uterine leiomyomata disease received a second UAE at 15 months due to recurrent pain after 12 months. At 17 months following the second UAE, she returned again because of pain in the left lower abdomen. At 107 months after the second UAE, no additional treatment was necessary and reported symptoms to be manageable. Patient no. 7 needed a hysterectomy at 72 months after UAE due to cervical leiomyomata growth and clinical symptom recurrence. Patient no. 5 with reported worsening of HRQOL and limited improvement in symptoms in short term became asymptomatic on long-term follow-up (45 months). The remaining patients $(n=6,75 \%)$ reported no additional treatments needed nor symptom recurrence at a median follow-up of 38.0 months (range 6-125). No adverse events were reported.

\section{Discussion}

\section{Summary of Clinical Findings}

This retrospective study demonstrated the efficacy and safety of UAE in women with symptomatic cervical leiomyomata, based on clinical outcomes with HRQOL, symptom severity scoring (SSS) and MR imaging. Significant reduction in the cervical leiomyomata volume was calculated related to a statistically significant decrease in the SSS at 3 months after UAE. Short-term improvement in symptom severity and HRQOL seems to be largest in the women with concurrent non-cervical leiomyomata disease. However, long-term outcomes displayed that this effect was not maintained. UAE infarction rates were ranging between 40 and $100 \%$. Six out of eight patients underwent a successful cervical leiomyomata UAE treatment. All of these patients with the exception of one showed a leiomyomata infarction rate of more than $80 \%$. Two of three patients with concurrent non-cervical leiomyomata disease received additional therapy because of recurrent or persisting symptoms. No complications occurred. 


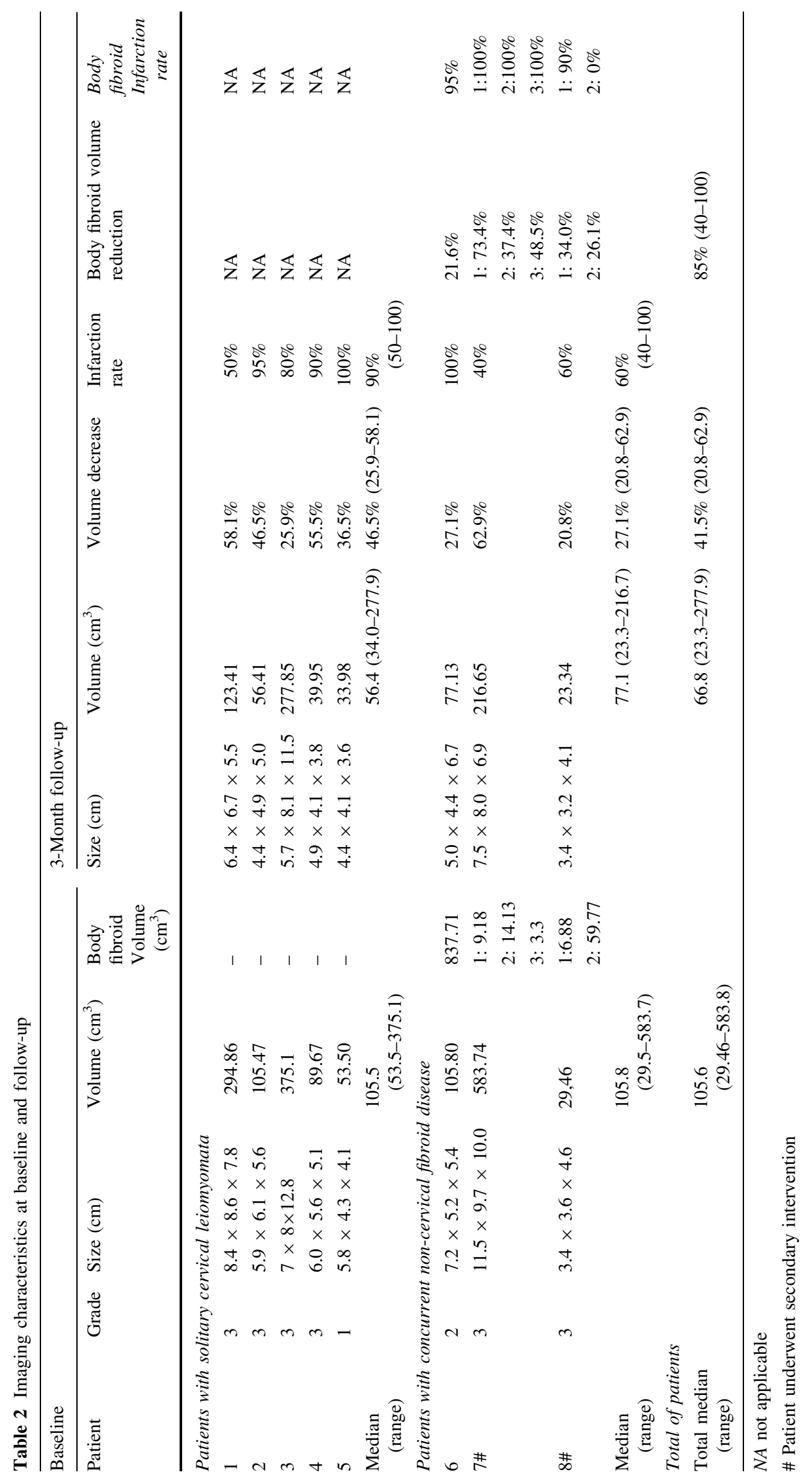


Fig. 2 Median cervical leiomyomata volume reduction $\left(\mathrm{cm}^{3}\right)$ until 3 months of followup compared to baseline
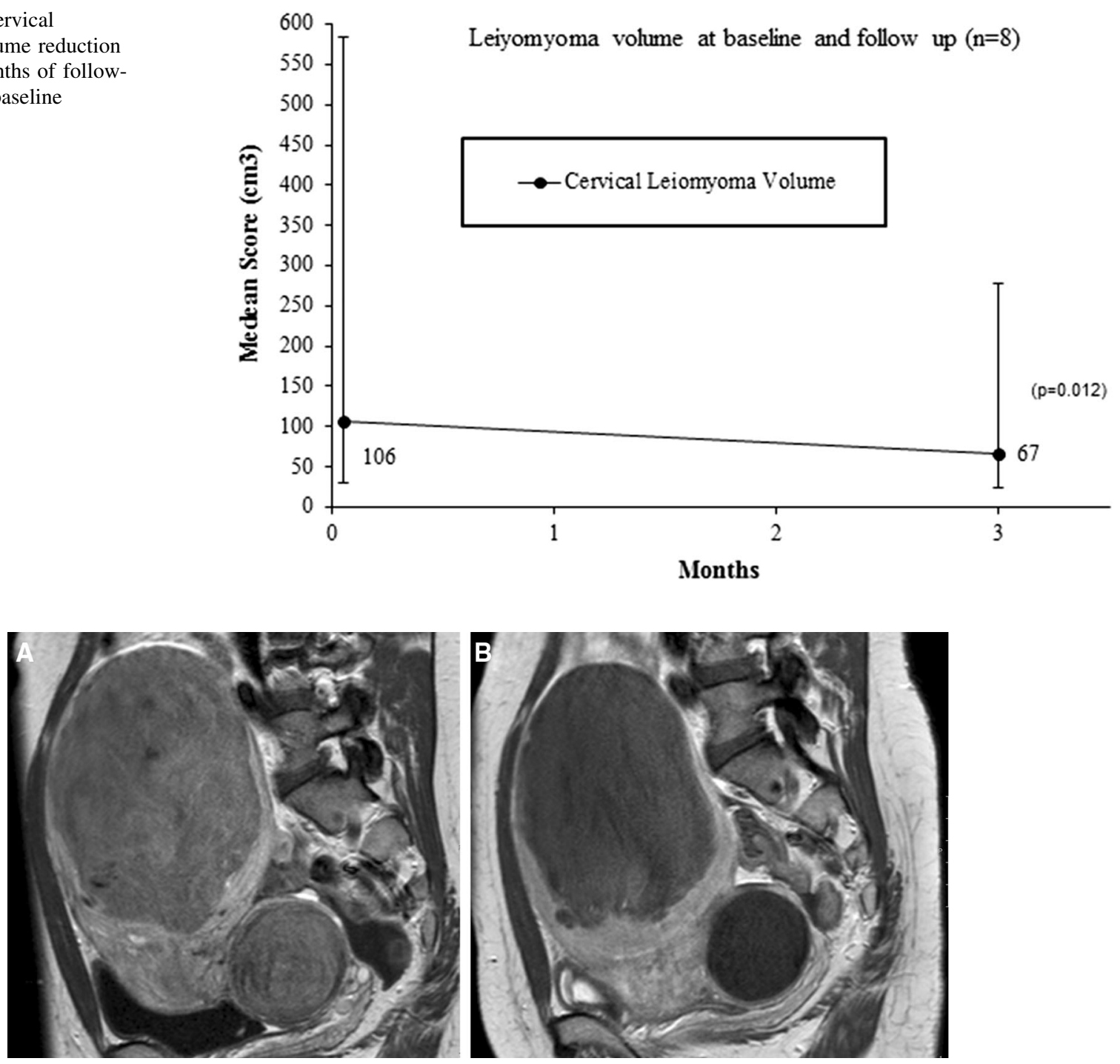

Fig. 3 MRI (SAG T1 - TSE - HR contrast + ) imaging of cervical leiomyomatas in combination with uterine body fibroids. Note Patient no. 6, MR images (sagittal T1 - TSE - HR + contrast) of leiomyomata in the uterine body and cervix. A Both the cervical leiomyomata $\left(106 \mathrm{~cm}^{3}\right)$ and the uterine body leiomyomata demonstrated full enhancement prior to UAE. B Follow-up imaging 3

\section{Interpretations of Outcomes}

Patients with a solitary cervical leiomyomata showed lower median improvement in HRQOL and symptom severity at short-term follow-up compared to women with concomitant uterine fibroids. This could be explained by the limited number of patients in this study and the effect of two patients with solitary cervical leiomyomata demonstrating low UFS-QOL scores, which may be explained by a lower infarction rate and accompanying non-cervical leiomyomata disease. As suggested by Aryani et al. [26], a potential cause of insufficient cervical leiomyomata infarction could be preexistent collaterals potentially also months after UAE with 5\% enhancement of the leiomyomata in the uterine body and no enhancement of the cervical leiomyomata, as a result of complete infarction after bilateral UAE $(2 \mathrm{cc} 700 \mu \mathrm{m}$, $4 \mathrm{cc} 900 \mu \mathrm{m}$ and $4 \mathrm{cc} 1200 \mu \mathrm{m}$ microspheres, Embozene $\left.{ }^{\mathrm{TM}}\right)$. The cervical leiomyomata volume 3 months after UAE was $77 \mathrm{~cm}^{3}$ with a volume reduction of $27 \%$

feeding the cervical leiomyomata. This was unfortunately not verifiable, because no specific DSA examination of the internal iliac arteries with their anterior divisions to the pelvis with potential collaterals was performed during the UAE procedures. Another cause of incomplete infarction might be the hypervascularity of the body/fundal leiomyomata, in which case the embolic agent might migrate to the uterus instead.

\section{Strengths and Limitations}

This is the second retrospective study published about UAE in women with symptomatic cervical leiomyomata, Kim 


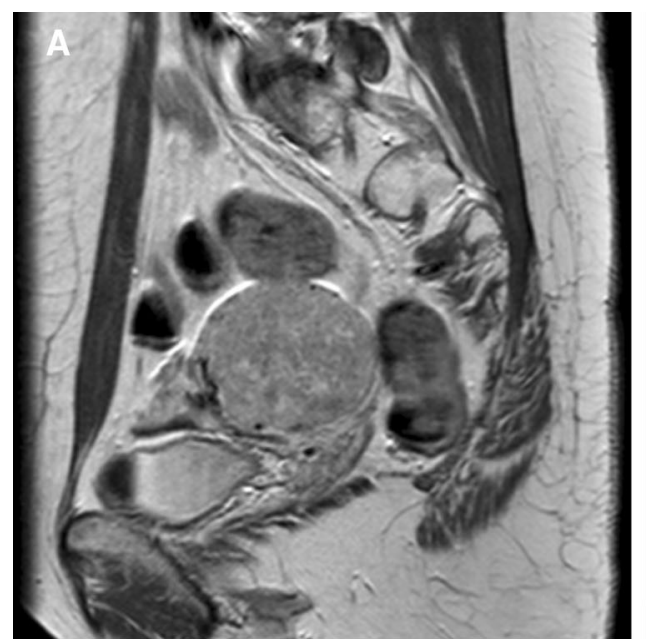

Fig. 4 MRI (SAG T1 - TSE - HR contrast + ) imaging of a solitary cervical leiomyomata. Note Patient no. 2, MR images (sagittal T1 - TSE - HR + contrast) of a single cervical leiomyomata in a 37-year-old patient with heavy menstrual blood loss and a wish to conceive. Cervix with a broad-based leiomyomata on the left. A The

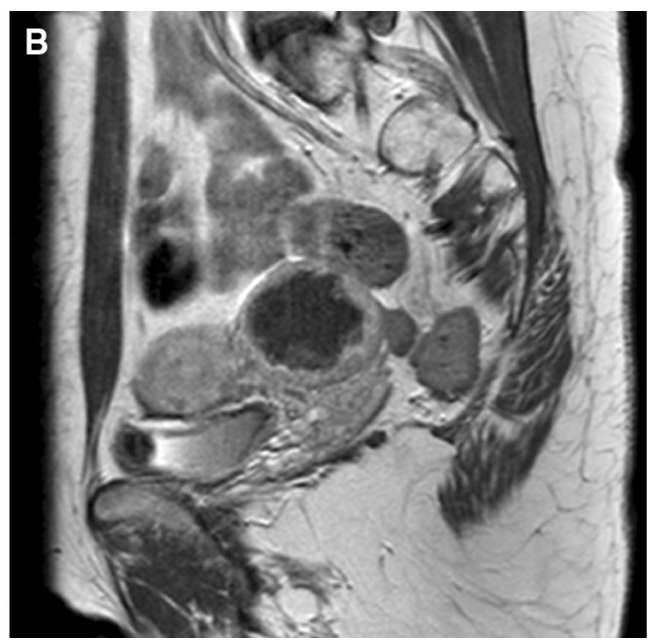

cervical leiomyomata $\left(106 \mathrm{~cm}^{3}\right)$ with full enhancement prior to UAE. B MR imaging 3 months after UAE showed 95\% infarction with an irregular enhancing rim. Unilateral left-side UAE with 2cc500, $2 \mathrm{cc700}$ and $3 \mathrm{cc} 900 \mu \mathrm{m}$ microspheres Embozene ${ }^{\mathrm{TM}}$; 47\% volume reduction $\left(56.4 \mathrm{~cm}^{3}\right)$
Fig. 5 Total quality of life and symptoms severity scores at baseline and 3 months of follow-up
Total QOL and Symptoms Severity Score $n=7$

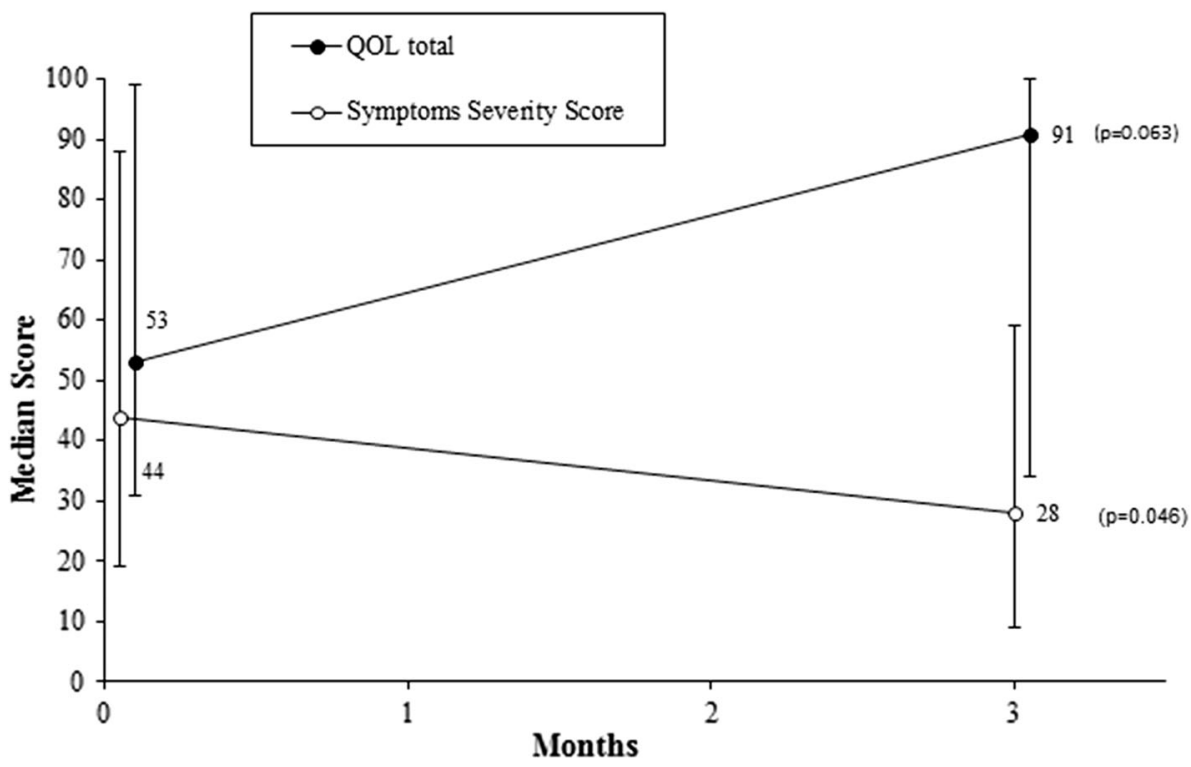

et al.'s study being the first [24]. Our study retrospectively examined the clinical outcome before and after UAE obtained by validated questionnaires, which were prospectively collected. All available imaging was evaluated by two radiologists, making outcomes more reliable. Only eight patients were included in this study, resulting in a limited sample size. Therefore, although the UAE results in symptomatic cervical leiomyomata favor this option as a treatment for women seeking uterine-sparing surgery, the limited sample size does not allow us to draw too strong conclusions. Larger high-quality trials should be conducted to confirm our results. However, this condition is rare; thus, reports like these remain important when counseling these patients.

\section{Comparison with Other Studies}

We are aware of two reports [24, 27] on UAE in the treatment of cervical leiomyomata. The first report compared effectiveness of UAE of cervical leiomyomata versus uterine fundal/body leiomyomata with imaging and stated that "the results of UAE were disappointing, indicating a need for caution in selecting and counseling patients for this treatment" [24]. At 3 months, they reported a total 
infarction in only $2 / 10(20 \%)$ patients and zero infarction in $2 / 10(20 \%)$ patients, with symptom improvement in $4 / 10$ (40\%) patients. They did not use a standardized validated questionnaire. Five out of nine patients showed a Grade I vascularity pattern, two Grade II and two Grade III vascularity pattern. Our cohort consists of eight patients with six Grade III vascularity patterns, one Grade II and one Grade I vascularity pattern.

Our study results demonstrated a higher treatment success rate. At 3 months, the symptom severity score (SSS) and HRQOL score improved in $7 / 7$ patients $(100 \%)$ and $5 / 7$ patients $(71 \%)$, respectively. Long-term satisfaction without additional therapy was achieved in $6 / 8$ patients (75\%). The difference in success rate may be explained by the leiomyomata vascularity (Grade III), a different UAE agent and the relatively larger size, and therefore, the relatively increased vascularization which might presumably lead to increased infarction compared to infarction rates of smaller fibroids with less vascularization and/or the described catheterization technique.

The second publication concerns the world's first reported UAE during pregnancy [27]. We hypothesized that the pregnancy itself would be an influencing factor on the cervical leiomyomata growth, which is why we excluded pregnant or postpartum patients in this study [28].

\section{Conclusion}

UAE in women with symptomatic cervical leiomyomata seems to be effective and safe with significant improvement in symptoms and quality of life. UAE is a valuable option for women seeking a non-surgical solution.

\section{Compliance with Ethical Standards}

Conflict of interest Dr. P.N.M. Lohle has a consultancy agreement with Boston Scientific. All other authors declare that they have no conflicts of interest.

Open Access This article is distributed under the terms of the Creative Commons Attribution 4.0 International License (http:// creativecommons.org/licenses/by/4.0/), which permits unrestricted use, distribution, and reproduction in any medium, provided you give appropriate credit to the original author(s) and the source, provide a link to the Creative Commons license, and indicate if changes were made.

\section{References}

1. Townsend DE, Sparkes RS, Baluda MC, McClelland G. Unicellular histogenesis of uterine leiomyomas as determined by electrophoresis by glucose-6-phosphate dehydrogenase. Am J Obstet Gynecol. 1970;107(8):1168-73.
2. Buttram VC Jr, Reiter RC. Uterine leiomyomata: etiology, symptomatology, and management. Fertil Steril. 1981;36(4):433-45.

3. Cramer SF, Patel A. The nonrandom regional distribution of uterine leiomyomas: a clue to histogenesis? Hum Pathol. 1992;23(6):635-8.

4. Tiltman AJ. Leiomyomas of the uterine cervix: a study of frequency. Int J Gynecol Pathol. 1998;17(3):231-4.

5. Stovall T. Myomectomy. In: Mann WJ, Stovall T, editors. Gynecologic surgery. New York: Churchill Livingstone; 1996. pp. $445-461$

6. Peker N, Gundogan S, Sendag F. Laparoscopic management of huge cervical myoma. J Minim Invasive Gynecol. 2016;24(3):345-6.

7. Sinha R, Sundaram M, Lakhotia S, Hegde A. Cervical myomectomy with uterine artery ligation at its origin. J Minim Invasive Gynecol. 2009;16(5):604-8.

8. Matsuoka S, Kikuchi I, Kitade M, Kumakiri J, Kuroda K, Tokita S, et al. Strategy for laparoscopic cervical myomectomy. J Minim Invasive Gynecol. 2010;17(3):301-5.

9. de Bruijn AM, Ankum WM, Reekers JA, Birnie E, van der Kooij SM, Volkers NA, et al. Uterine artery embolization vs hysterectomy in the treatment of symptomatic uterine fibroids: 10-year outcomes from the randomized EMMY trial. Am J Obstet Gynecol. 2016;215(6):745e1-12.

10. Edwards RD, Moss JG, Lumsden MA, Wu O, Murray LS, Twaddle $S$, et al. Uterine-artery embolization versus surgery for symptomatic uterine fibroids. $N$ Engl J Med. 2007;356(4):360-70.

11. Goodwin SC, Spies JB, Worthington-Kirsch R, Peterson E, Pron $\mathrm{G}, \mathrm{Li} \mathrm{S}$, et al. Uterine artery embolization for treatment of leiomyomata: long-term outcomes from the FIBROID Registry. Obstet Gynecol. 2008;111(1):22-33.

12. Hehenkamp WJ, Volkers NA, Donderwinkel PF, de Blok S, Birnie E, Ankum WM, et al. Uterine artery embolization versus hysterectomy in the treatment of symptomatic uterine fibroids (EMMY trial): peri- and post-procedural results from a randomized controlled trial. Am J Obstet Gynecol. 2005;193(5):1618-29.

13. Moss JG, Cooper KG, Khaund A, Murray LS, Murray GD, Wu O, et al. Randomised comparison of uterine artery embolisation (UAE) with surgical treatment in patients with symptomatic uterine fibroids (REST trial): 5-year results. BJOG. 2011;118(8):936-44.

14. van der Kooij SM, Hehenkamp WJ, Volkers NA, Birnie E, Ankum WM, Reekers JA. Uterine artery embolization vs hysterectomy in the treatment of symptomatic uterine fibroids: 5 -year outcome from the randomized EMMY trial. Am J Obstet Gynecol. 2010;203(2):105-13.

15. Pilarczyk K. Variability of the course of the uterine artery and its branches within the broad ligament and vascularization of uterine walls depending on a woman's age in light of anatomical, radiologic and microangiographic studies. Ann Acad Med Stetin. 1995;41:43-55.

16. DA Moore KL, Agur AM. Clinically oriented anatomy. 6th ed. Philadelphia: Lippincott Williams and Wilkins; 2008.

17. Bereza T, Tomaszewski KA, Walocha J, Mizia E, Bachul P, Chmielewski P. Vascular architecture of the human uterine cervix, as assessed in light- and scanning electron microscopy. Folia Morphol (Warsz). 2012;71(3):142-7.

18. Bereza T, Skrzat J, Brzozowska I, Maduzia D, Matuszyk A, Chmielewski P, et al. Blood supply of human uterine cervix-a SEM study. Folia Med Cracov. 2013;53(4):5-12.

19. Harding G, Coyne KS, Thompson CL, Spies JB. The responsiveness of the uterine fibroid symptom and health-related quality of life questionnaire (UFS-QOL). Health Qual Life Outcomes. 2008;6:99. 
20. Spies JB, Coyne K, Guaou Guaou N, Boyle D, Skyrnarz-Murphy $\mathrm{K}$, Gonzalves SM. The UFS-QOL, a new disease-specific symptom and health-related quality of life questionnaire for leiomyomata. Obstet Gynecol. 2002;99(2):290-300.

21. Siskin GP, Beck A, Schuster M, Mandato K, Englander M, Herr A. Leiomyoma infarction after uterine artery embolization: a prospective randomized study comparing tris-acryl gelatin microspheres versus polyvinyl alcohol microspheres. J Vasc Interv Radiol. 2008;19(1):58-65.

22. Smeets AJ, Nijenhuis RJ, van Rooij WJ, Weimar EA, Boekkooi PF, Lampmann LE, et al. Uterine artery embolization in patients with a large fibroid burden: long-term clinical and MR follow-up. Cardiovasc Interv Radiol. 2010;33(5):943-8.

23. Goodwin SC, Bonilla SC, Sacks D, Reed RA, Spies JB, Landow WJ, et al. Reporting standards for uterine artery embolization for the treatment of uterine leiomyomata. J Vasc Interv Radiol. 2003;14(9 Pt 2):S467-76.
24. Kim MD, Lee M, Jung DC, Park SI, Lee MS, Won JY, et al. Limited efficacy of uterine artery embolization for cervical leiomyomas. J Vasc Interv Radiol. 2012;23(2):236-40.

25. Dariushnia SR, Nikolic B, Stokes LS, Spies JB. Society of interventional radiology standards of practice C. Quality improvement guidelines for uterine artery embolization for symptomatic leiomyomata. J Vasc Interv Radiol. 2014;25(11):1737-47.

26. Aranyi Z, Patanyik M, Nemeth G, Scholz M, Stumpf J. Post mortem uterine arteriography and in vivo angiographic diagnosis. Acta Morphol Hung. 1985;33(3-4):219-25.

27. Lohle PN, Boekkooi PF, Fiedeldeij CA, Berden HJ, de Jong W, Reekers JA, et al. Selective embolisation of a heavily bleeding cervical fibroid in a pregnant woman. Cardiovasc Interv Radiol. 2015;38(6):1649-53.

28. Benaglia L, Cardellicchio L, Filippi F, Paffoni A, Vercellini P, Somigliana E, et al. The rapid growth of fibroids during early pregnancy. PLoS ONE. 2014;9(1):e85933. 